Research Article

\section{Current childhood cancer survivor long- term follow-up practices in South Africa}

\author{
Anel van Zyl1*, Paul C Rogers ${ }^{2}$ and Mariana Kruger $^{1}$ \\ ${ }^{1}$ Department of Paediatrics and Child Health, Faculty of Medicine and Health Sciences, University \\ of Stellenbosch, Tygerberg Hospital, Cape Town, South Africa \\ ${ }^{2}$ Department of Pediatrics, University of British Columbia, Vancouver, Canada and Department of \\ Paediatrics and Child Health, Faculty of Medicine and Health Sciences, University of Stellenbosch, \\ Tygerberg Hospital, Cape Town, South Africa
}

\section{Summary}

Background: The number of childhood cancer survivors (CCSs) is increasing due to improved survival. Most suffer at least one treatment-related late effect, even decades after treatment, thus lifelong long-term follow-up (LTFU) care is a necessity. Currently no standardized LTFU programme for CCSs exists in South Africa.

Study purpose: This study investigated current LTFU care of CCSs in South Africa.

Methods: A survey was conducted amongst 31 South African paediatric oncologists using the SurveyMonkey ${ }^{\mathrm{TM}}$ online tool. Information obtained included: training/experience, LTFU practices, late effects knowledge and opinion regarding the importance of a standardized LTFU programme.

Results: The response rate was $74 \%(23 / 31)$. Respondents had an average of 9 years' experience. All $(22 / 23 ; 96 \%)$ regarded LTFU as important. Only half $(12 / 23 ; 52 \%)$ discussed late effects at diagnosis. Infertility and second malignancy risks were discussed by a third. Less than half $(48 \%)$ used LTFU guidelines; the majority $(9 / 11 ; 82 \%)$ adjusted them to the local context. Most survivors were followed by a paediatric oncologist (17/23; $74 \%)$.

About half of respondents (47.8\%) shared LTFU with colleagues in private practice $(50 \%)$, secondary $(66.7 \%)$ or primary care facilities $(25 \%)$. Almost half of respondents $(10 / 23 ; 43.5 \%)$ regarded their late effects knowledge and LTFU experience as good, $8 / 23(34.8 \%)$ as adequate and $3 / 23(13 \%)$ as inadequate. All agreed that a national LTFU programme would be very important $(87 \%)$ or important $(13 \%)$. Almost half of the respondents $(48 \%)$ understood what a Survivorship Passport was.

Conclusion: It is essential to develop a national standardized LTFU programme for CCSs in South Africa to ensure appropriate care for all survivors.

\section{More Information}

*Address for Correspondence: Anel van Zyl, Department of Paediatrics and Child Health, Faculty of Medicine and Health Sciences, University of Stellenbosch, Tygerberg Hospital, Cape Town, South Africa, Tel: +2721 9389444; +27823728622; Email: vanzyla@sun.ac.za

Submitted: 13 January 2020

Approved: 28 January 2020

Published: 29 January 2020

How to cite this article: Zyl AV, Rogers PC, Kruger M. Current childhood cancer survivor long-term follow-up practices in South Africa. J Adv Pediatr Child Health. 2020; 3: 001-007.

DOI: dx.doi.org/10.29328/journal.japch.1001008 ORCID: https://orcid.org/0000-0003-3370-0874

Copyright: (C) 2020 Zyl AV, et al. This is an open access article distributed under the Creative Commons Attribution License, which permits unrestricted use, distribution, and reproduction in any medium, provided the original work is properly cited.

\section{Check for updates}

OPEN ACCESS

\section{Introduction}

Improvement of childhood cancer survival is one of the most impressive success stories of modern medical science $[1,2]$. The overall survival rate in high-income countries (HIC) has increased to $80 \%$ and the number of childhood cancer survivors is continually increasing [1,3-5]. Unfortunately, survival rates are still poor in low and middle-income countries (LMIC) due to numerous factors [6,7]. In South Africa, just over 1000 cases of childhood cancer are diagnosed annually; at least half will go on to require long-term followup (LTFU) care [8]. Currently no formal LTFU programme for childhood cancer survivors exists in South Africa.

\section{Background}

Childhood cancer survivors face significant and potentially debilitating late side effects from both the previous cancer and its treatment. Approximately $75 \%$ will suffer at least one treatment-related late effect, [9-11], including psychosocial problems, second malignancies, renal or liver impairment, endocrinopathy and cardiomyopathy [12]. Late effects may only occur 10-40 years after completion of therapy [9]. Previously most children were followed for 5-10 years after treatment; the modern trend is to enter patients into a lifelong LTFU programme [13-15]. 
There are many unanswered questions regarding the ideal LTFU model, even in HICs. In 2010 major role players formed the International late effects of childhood cancer guideline harmonization group in order to provide evidencebased (when available) or expert opinion international guidelines [16]. A novel concept is a Survivorship Passport of which one example is the internet-based Passport for Care (PFC), developed by the National Cancer Institute, the Children's Oncology Group (COG) and the National Childhood Cancer Survivor Study in the United States $[17,18]$. A health care provider can securely enter information related to the survivor's clinical and treatment details. Algorithms then produce individualized recommendations regarding followup visits. This tool doubles as a source of information for the survivors (e.g. support groups).

Very little about this increasingly important subject has been published from LMICs. This study has investigated current practices regarding LTFU of childhood cancer survivors in South Africa with the eventual aim of developing an appropriate local LTFU model.

\section{Materials and methods}

A survey was conducted, using the secure SurveyMonkey ${ }^{\mathrm{TM}}$ online tool, to document the current LTFU practice of childhood cancer survivors in South Africa. All paediatric oncologists ( $n$ = 31) and members of the South African Children's Cancer Study Group (SACCSG) [19] were invited via email to complete the survey anonymously (3 reminders were sent). The survey was mainly quantitative in design with 25 questions (selfdesigned): 24 close-ended multiple-choice format questions (7 Yes/No-type answers; some with expanded options and 17 with several answer options given) and 1 quantitative question) (Appendix A). The following topics were explored: training and experience, the importance of LTFU, practices with regards to monitoring and management of late effects and the use of LTFU guidelines., the type of LTFU model utilised and knowledge of late effects and late effects monitoring. Lastly, respondents were questioned about their view of the importance of a standardized LTFU programme relevant for South Africa, their knowledge regarding a Survivorship Passport and its potential benefit for childhood cancer survivors in South Africa.

Frequencies and cross tabulation were performed using IBM SPSS Statistics version 25. The Health Research Ethics Committee of Faculty of Medicine and Health Sciences, Stellenbosch University provided approval for this study.

\section{Results}

The survey response rate was $74 \%$ (23/31). Respondents had an average of 9 years' experience (median 8 years; range less than 1 year to 31 years) (Tables 1,2). More than half (61\%) of respondents had at least 5 years of experience: $39.1 \%$ had less than 5 years' experience, $21.7 \%$ 5-9 years,

\begin{tabular}{|c|c|}
\hline Question topic & Results \\
\hline Years of paediatric oncology experience & $\begin{array}{l}\text { Mean } 9.3 \text { years; median } 8 \text { years; } \\
\text { range }<1 \text { year - } 31 \text { years }\end{array}$ \\
\hline Received paediatric oncology formal training & $18 / 23(78.2 \%)$ \\
\hline Paediatric oncology training in South Africa & $17 / 18(94.4 \%)$ \\
\hline Received formal late effects training & 6/18 (33.3\%) \\
\hline \multirow{2}{*}{ Respondents' view of importance of LTFU } & Very important (15/23; 65.2\%) \\
\hline & Important 7/23 (78.3\%) \\
\hline $\begin{array}{l}\text { Respondents' view of importance of } \\
\text { monitoring for late effects }\end{array}$ & $21 / 23(91.3 \%)$ \\
\hline \multirow{4}{*}{ Knowledge and experience regarding LTFU } & $\begin{array}{l}\text { Very good and very comfortable } \\
\qquad 2 / 23(8.7 \%)\end{array}$ \\
\hline & $\begin{array}{l}\text { Good, but would like to improve } \\
\qquad 10 / 23(43.5 \%)\end{array}$ \\
\hline & $\begin{array}{l}\text { Adequate, but would like to improve } \\
\qquad 8 / 23(34.8 \%)\end{array}$ \\
\hline & $\begin{array}{l}\text { Inadequate, would like to improve } \\
\qquad 3 / 23(13 \%)\end{array}$ \\
\hline
\end{tabular}

Table 2: Current paediatric oncology LTFU practices in South Africa and future.

\begin{tabular}{|c|c|}
\hline Question topic & Results \\
\hline Do not use specific LTFU guidelines & $12 / 23(52.2 \%)$ \\
\hline $\begin{array}{l}\text { Do not strictly adhere to LTFU } \\
\text { guidelines for specific reasons }\end{array}$ & 9/11 (81.8\%) \\
\hline \multirow{2}{*}{ Person conducting LTFU } & Paediatric oncologist 17/23 (73.9\%) \\
\hline & Referral to another colleague $6 / 2326.1 \%$ ) \\
\hline \multirow{6}{*}{ Duration of LTFU } & $\begin{array}{c}10 \text { years with subsequent referral for annual } \\
\text { follow-up in private or public health sector } \\
3 / 23(13 \%)\end{array}$ \\
\hline & $\begin{array}{l}10 \text { years; then discharge from LTFU clinic } \\
6 / 23(26.1 \%)\end{array}$ \\
\hline & $\begin{array}{l}\text { Follow-up until } 18 \text { years of age; transfer of } \\
\text { selected patients to adult services } 6 / 23 \\
\qquad(26.1 \%)\end{array}$ \\
\hline & $\begin{array}{l}\text { Follow-up until } 18 \text { years of age; transfer of } \\
\text { all patients to adult services } 1 / 23(4.31 \%)\end{array}$ \\
\hline & $\begin{array}{l}\text { Follow-up for } 5 \text { years, then discharge from } \\
\text { LTFU } 2 / 23(13 \%)\end{array}$ \\
\hline & Other $5(21.7 \%)$ \\
\hline \multirow{3}{*}{$\begin{array}{l}\text { Alternate LTFU care with a colleague } \\
\qquad 12 / 23(52.2 \%)\end{array}$} & Colleague in private practice $6 / 12(50 \%)$ \\
\hline & $\begin{array}{l}\text { Colleague in a secondary hospital 8/12 } \\
(66.7 \%)\end{array}$ \\
\hline & $\begin{array}{l}\text { Colleague in a primary care clinic } 3 / 12 \\
\qquad(25 \%)\end{array}$ \\
\hline \multirow{2}{*}{$\begin{array}{l}\text { Importance of a standardized LTFU } \\
\text { programme for South Africa }\end{array}$} & Very important $20 / 23$ (87\%) \\
\hline & Important 3/23 (13\%) \\
\hline $\begin{array}{c}\text { Would it be helpful for survivors to be } \\
\text { issued with a so-called Survivorship } \\
\text { Passport? }\end{array}$ & Yes $23 / 23(100 \%)$ \\
\hline
\end{tabular}

$17.4 \% 10-14$ years and $21.7 \% 15$ years or more. Most (18/23; $78 \%$ ) received formal training in paediatric oncology, 3 obtained registration under the so-called "grandfather clause" of the local Health Professional Council of South Africa, based on experience and 2 did not have any formal training. Almost all respondents except one, received training in South Africa and the majority $(20 / 23 ; 87 \%)$ have never worked or trained outside of South Africa.

Two thirds of respondents did not receive any formal training regarding late effects of childhood cancer and its treatment, but almost all $(22 / 23 ; 96 \%)$ regarded LTFU as either very important or important. The vast majority of 
respondents $(21 / 23 ; 91 \%)$ indicated that a specific focus on monitoring for late effects in the clinic is very important or important, while two respondents did not focus on this in their respective follow-up clinics. Two respondents usually assessed the risk for late effects, depending on previous diagnosis, treatment received and complications that occurred the day or week before a patient's clinic visit. Most $(18 / 23$; $78 \%$ ) assessed the risk just before they saw the patient or during the consultation. Three respondents indicated that they had no time to assess this risk for patients and would deal with late effects as they occur.

Just over half of the group $(12 / 23 ; 52 \%)$ discussed late effects with patients and their families at diagnosis, while four respondents had this discussion at the end of treatment and before LTFU commenced. Another four respondents discussed late effects at the first LTFU appointment, while two only discussed it when a parent specifically asked about late effects. One respondent raised the topic only when a late effect was suspected or had already occurred. The potential risks of infertility and second malignancy were discussed in as much detail as appropriate for the patient and family by only a third of participants. Fertility risks were mentioned only briefly by a third of respondents and second malignancies by half of respondents. Four respondents did not usually mention the risk of infertility and one did not mention the risk of a second neoplasm.

Less than half of the respondents (48\%) use LTFU guidelines. The guidelines used included those from the COG (36\%), [20] the Dutch Cancer Oncology Group (9\%), [21] the United Kingdom Therapy-based LTFU guidelines (18\%) [22] and institutional guidelines (36\%). The majority of respondents $(9 / 11 ; 82 \%)$ who used specific guidelines did not strictly adhere to them. Reasons for having adjusted the guidelines were lack of availability of investigations (6/9; $67 \%$ ), lack of patient ability to adhere to the follow-up plan $(4 / 9 ; 44 \%)$, budget limitations in the state sector $(4 / 9 ; 44 \%)$, to decrease costs for patients with medical insurance $(3 / 9$; $33 \%$ ), the belief that investigations are not required as often as the guidelines indicate $(2 / 9 ; 22 \%)$ and concern regarding additional radiation exposure $(1 ; / 9 ; 11 \%)$.

Most survivors were primarily followed up by a paediatric oncologist $(17 / 23 ; 74 \%), 6$ respondents referred some patients to another colleague (general practitioner, general paediatrician, endocrinologist, gynaecologist, nephrologist, neurologist, orthopaedic surgeon, radio-oncologist) to continue follow-up. Survivors who had developed a late effect, were mostly referred to the relevant subspecialty $(11 / 23$; $48 \%$ ) or a sub-specialist was consulted and follow-up was continued by the paediatric oncologist (9/23; 39\%). Five respondents managed late effects themselves, mostly because sub-specialty services were not available at their institutions.

Respondents used a wide range of follow-up models.
Twelve respondents (52.2\%) chose to continue followup for 10 years after diagnosis with or without transfer to adult services. A quarter $(6 / 23 ; 26.1 \%)$ followed patients until 18 years of age and then transferred selected patients to the adult haematology/oncology service. One respondent transferred all patients at 18 years and older to the adult service. Two respondents discharged patients after a 5-year follow-up period; another mentioned that they were forced to end follow-up after 5 years in the state sector due to a lack of capacity and resources. Just less than half of respondents $(47.8 \%)$ alternated follow-up care with another colleague in private practice $(50 \%)$, in a secondary hospital $(66.7 \%)$ or in a primary care clinic (25\%). Almost half of respondents $(10 / 23 ; 43.5 \%)$ indicated that their knowledge regarding late effects and experience in the LTFU care of childhood cancer survivors was good, but that they would like to improve. About a third $(8 / 23 ; 34.8 \%)$ judged their knowledge to be adequate with room for improvement and three respondents rated it as inadequate. Only two experienced respondents (10-14 years and plus 15 years' experience respectively) felt very comfortable conducting the LTFU care of survivors. Of the respondents with less than 5 years' experience, $44,4 \%$ rated their knowledge as adequate, while a third regarded it as good. In the 5-9 years' experience category, 60\% rated their knowledge as adequate and $40 \%$ as good. The more experienced respondents (half of those with 10-14 years' experience and $60 \%$ with 15 years' and more experience) regarded their knowledge as 'good'.

All agreed that a standardized national LTFU program would be either very important $(87 \%)$ or important $(13 \%)$ for South Africa. Just less than half of the respondents (48\%) understood what a Survivorship Passport was, but once the concept was explained, all agreed that such a document would be very helpful for a childhood cancer survivor to receive.

\section{Discussion}

The topic of LTFU and late effects of childhood cancer treatment is as important as attaining a good survival rate. Once a child is cured of cancer, the goal is for him/her to have a life as healthy as possible and hopefully free of sequelae of cancer treatment.

In the past two decades, LTFU programmes and late effects research have continued to expand exponentially in HICs and many large survivor databases have been created [23-33]. In North America, most participating paediatric haematology/ oncology training centres indicated that their fellows needed to complete a mandatory survivorship rotation and attend survivorship lectures [34]. The most significant barrier identified was lack of time for fellows to attend these training opportunities, even in these well-resourced centres.

In a study that examined the barriers to LTFU in an LMIC by means of a survey amongst 21 Turkish paediatric oncology centres, $66 \%$ of respondents indicated that inadequate 
education about survivorship was provided to fellows due to a heavy work burden and lack of a specific LTFU clinic [35]. Inadequate training on late effects in LMICs could also be explained due to greater training focus on early diagnosis, strategies to improve supportive care and outcome, plus striving to improve capacity with harmonization of treatment protocols.

In this study, the views of the mostly locally trained group of experienced participants reflect the degree of focus on late effects of childhood cancer in the various paediatric oncology training programmes in South Africa. Despite the fact that the topic of late effects is currently included on the blueprint for the paediatric oncology sub-specialist qualification [36], only 3 out of the 9 paediatric oncologists who qualified in the last 5 years have received formal training.

Despite this lack of formal training about late effects, almost all South African respondents regarded LTFU of survivors with a specific focus on monitoring for late effects as either important or very important. Through practical experience and increasing exposure to this topic in the literature and during conferences, paediatric oncologists realize the necessity of a meticulous LTFU programme.

Most respondents in this study do a risk assessment just before seeing a survivor in the clinic or during the consultation. However, this process takes time, a precious commodity in a busy paediatric oncology unit, especially if all clinical information is not easily accessible. Centres in HICs describe this time burden as a barrier to providing an appropriate LTFU plan to patients. In a study that included 8 LIVESTRONG ${ }^{\mathrm{TM}}$ Centres of Excellence in Cancer Survivorship Network in America, 53.8\% of sites reported spending 31-60 minutes on reviewing previous treatment of breast cancer survivors. An additional $\leq 30$ minutes was spent on reviewing it together with the patient [37].

It is desirable to start the discussion about late effects already at diagnosis. Some late effect risks such as infertility and the development of a second malignancy are sensitive topics to discuss with parents of a young child newly diagnosed with cancer and may provoke significant anxiety. In HICs the risk of infertility is not a popular subject of discussion at diagnosis. Paediatric oncologists in the United Kingdom discussed the risk of infertility with only $37 \%$ of patients [38], compared to $61 \%$ of a medical group including paediatric oncologists at Duke University, United States of America [39]. Reasons for no discussion included young age, an insignificant risk of infertility, poor prognosis, the need for urgent treatment and patients already having children. Childhood cancer survivors in the Netherlands were found to worry more about fertility than healthy controls [40], emphasizing the need to empower patients with information. In this local study, only a third of respondents discussed these late effects with patients and families in appropriate detail. The reason for this lack of discussion was not explored in this study. It is however a well-known fact that childhood cancer survivors do not remember all information given to them about their diagnosis and treatment [41]. About 50\% do not recall any counselling about infertility $[42,43]$, therefore ongoing discussion during LTFU visits is essential to discuss patients' risk profiles, perform appropriate surveillance and provide the necessary medical care. A structured LTFU programme provides an ideal setting during which these conversations can continue after completion of treatment.

A similar trend exists for limited knowledge regarding the risk of developing a second malignant neoplasm. Less than a third of childhood cancer survivors (28\%) who were treated at the Groningen University Medical Centre were aware of their risk of a second malignant neoplasm (SMN) [44]. It is important to discuss this risk factor with patients and their families, as their LTFU programme should be adjusted based on the individual risk for an SMN. Secondary surveillance for SMNs through a structured LTFU programme is essential in order to positively influence long-term outcomes.

Several LTFU guidelines are available to assist in riskassessment and monitoring for late effects. Approximately half of respondents used specific guidelines, most commonly individual institutional guidelines and that of the COG. Most adapted the guidelines for various cost-related and capacity reasons. LTFU guidelines are essential for providing the same high-quality health care to all survivors [16], but it is clear that guidelines developed for HICs are not appropriate or implementable for LMICs such as South Africa.

Currently there is no standard childhood cancer LTFU model in South Africa. The majority of participants reported a follow-up period of 10 years or until 18 years of age, with subsequent transfer of selected patients to the adult service. This is in line with current international recommendations of life-long follow-up [13-15]. A similar practice was reported in Korea with a mean LTFU period of childhood cancer survivors of 10.4 years after diagnosis [45]. Slightly shorter mean follow-up periods were reported in the Singapore Childhood Cancer Survivor Study (5.5 years) [46], Thailand (7.2 years) [47] and South-India (8 years) [48]. However, there is no global consensus on what the optimal LTFU model should be and how the different models may affect outcome. Lack of resources and capacity are known barriers to childhood cancer management in LMICs [6] and thus also to LTFU programmes. The focus of childhood cancer in most LMICs is to improve (early) diagnosis and survival, while the LTFU care of survivors currently enjoys less attention.

Shared care can be defined as a partnership between the paediatric oncologist and a colleague in a primary or secondary level institution or in the private sector. Blaauwbroek. et al. reported that a shared care model in the Netherlands was feasible with $88 \%$ of survivors and $82 \%$ of family physicians 
being satisfied [49]. A follow-up study showed that this model is enhanced by a web-based survivor care plan, accessible to both the family physician and survivor [50]. It is important that the paediatric oncologist provides and discusses a detailed follow-up plan with the colleague sharing the follow-up care of a patient [51]. Almost half of local paediatric oncologists practiced a shared care model with colleagues in other institutions or in private practice. In South Africa with only 31 paediatric oncologists, there is no capacity for survivors to be followed solely by them and shared care should be implemented in South Africa. This necessitates a detailed LTFU plan provided by the primary paediatric oncologist with good communication with the colleagues assisting with shared LTFU care. A survivorship passport would be ideal to ensure that information is available and informative at all times.

In a Japanese study amongst paediatric oncologists, it was found that their knowledge regarding late effects could be improved [52]. Similarly more than 600 COG members with a median of 14 years of experience took part in a knowledgebased survey. A significant percentage (67\%) were unable to make correct surveillance recommendations for a patient case scenario, confirming unfamiliarity with existing LTFU guidelines [53]. In this study, as expected, South African paediatric oncologists with at least 10 years' experience were more comfortable with their knowledge of the LTFU of childhood cancer survivors. It would be important to provide training to all paediatric oncology fellows on the implementation and use of a LTFU programme in South Africa.

All participants agreed that the development of a national standardized LTFU programme would be very important or important. Such a programme would aid in improving the knowledge of paediatric oncologists and their level of comfort in caring for long-term survivors. The provision of and discussion about survivorship passports or care plans would vastly improve the knowledge of childhood cancer survivors concerning potential late effects and the importance of LTFU. In countries where a survivorship passport or care plan exists, patients and families found it very valuable and thought that it helped in making decisions regarding the survivor's LTFU [54]. The majority of patients (83.3\%) gained new information from the plan.

This is the first study to document current LTFU practices for childhood cancer survivors in South Africa. The weakness of this study is the small number of participants, but the majority (74\%) of local paediatric oncologists participated.

The results of this study forms the basis of a longitudinal plan, which includes a series of publications about late effects in a cohort of childhood cancer survivors in South Africa. The ultimate aim is to develop a standardized, structured and appropriate LTFU plan, including a survivorship passport, for all childhood cancer survivors in South Africa. This LTFU plan would ensure appropriate surveillance for late effects and early intervention upon detection in order to improve healthrelated quality of life.
This LTFU care of childhood cancer survivors should be incorporated into the planned National Health Insurance programme to ensure that all survivors receive standardized and appropriate care. A tailored LTFU programme [55] would advise the referral of survivors with no/minimal complications and a low/intermediate risk for late effects to primary or secondary care level physicians. We would anticipate that only survivors with complex problems would be seen at tertiary care hospitals, where there is adequate access to paediatric subspecialist care where necessary.

\section{Conclusion}

Long-term follow-up of childhood cancer survivors is as important as their cancer treatment and supportive care. Paediatric oncologists should receive adequate training in the care of survivors after completion of cancer treatment and be familiar with current LTFU guidelines. It is essential to develop a national standardized LTFU programme for childhood cancer survivors in South Africa in the context of the healthcare system and to incorporate it into the planned National Health Insurance programme to ensure appropriate care for all survivors.

\section{Acknowledgements}

The authors wish to thank the South African paediatric oncology community for taking part in this survey and acknowledge Dr Kristin C Marr (University of British Columbia and BC Children's Hospital) for her valuable input.

This piece of work was partially or fully funded by the South African Medical Research Council with grant number: 57041.

\section{Financial support}

The Degree from which this study emanated was funded by the South African Medical Research Council under the BONGANI MAYOSI NATIONAL HEALTH SCHOLARS PROGRAM. The content of any Publications from any studies during this Degree are solely the responsibility of the authors and do not necessarily represent the official views of the South African Medical Research Council.

\section{References}

1. http://www.cancerresearchuk.org/health-professional/cancerstatistics/childrens-cancers\#heading-Two. 2019.

2. O'Leary M, Krailo M, Anderson JR, Reaman GH. Children's Oncology Group. Progress in childhood cancer: 50 years of research collaboration, a report from the Children's Oncology Group. Semin Oncol. 2008; 35: 484-493

PubMed: https://www.ncbi.nlm.nih.gov/pubmed/18929147

3. Ward E, De Santis C, Robbins A, Kohler B, Jemal A. Childhood and adolescent cancer statistics, 2014. CA Cancer J Clin. 2014; 64: 83-102. PubMed: https://www.ncbi.nlm.nih.gov/pubmed/24488779

4. https://childrenscancer.canceraustralia.gov.au/about-childrens cancer/statistics. 2019. 
5. Gatta G, Botta L, Rossi S, Aareleid T, Bielska-Lasota M, et al. Childhood cancer survival in Europe 1999-2007: results of EUROCARE-5-a population-based study. Lancet Oncol. 2014; 15: 35-47.

PubMed: https://www.ncbi.nlm.nih.gov/pubmed/24314616

6. Kruger $M$, Hendricks $M$, Davidson $A$, Stefan $C D$, van Eyssen $A L$, et al Childhood cancer in Africa. Pediatr Blood Cancer. 2014; 61: 587-592. PubMed: https://www.ncbi.nlm.nih.gov/pubmed/24214130

7. Israels $\mathrm{T}$, Challinor J, Howard S, Arora RH. Treating children with cancer worldwide-challenges and interventions. Pediatrics. 2014; 136 607-610.

PubMed: https://www.ncbi.nlm.nih.gov/pubmed/26371201

8. Stones DK, De Bruin GP, Esterhuizen TM, Stefan DC. Childhood cancer survival rates in two South African units. S Afr Med J. 2014; 104: 501504.

PubMed: https://www.ncbi.nlm.nih.gov/pubmed/25214053

9. Oeffinger KC, Mertens AC, Sklar CA, Kawashima T, Hudson MM, et al. Chronic health conditions in adult survivors of childhood cancer. N Engl J Med. 2006; 355: 1572-1582.

PubMed: https://www.ncbi.nlm.nih.gov/pubmed/17035650

10. Armstrong GT, Kawashima T, Leisenring W, Stratton K, Stovall M, et al Aging and risk of severe, disabling, life-threatening, and fatal events in the childhood cancer survivor study. J Clin Oncol. 2014; 32: 1-22. PubMed: https://www.ncbi.nlm.nih.gov/pubmed/24638000

11. Geenen MM, Cardous-Ubbink MC, Kremer LC, van den Bos C, van der $\mathrm{Pal} \mathrm{HJ}$, et al. Medical assessment of adverse health outcomes in Longterm survivors of childhood cancer. JAMA. 2007; 297: 2705-2715. PubMed: https://www.ncbi.nlm.nih.gov/pubmed/17595271

12. Children's oncology group. Long-term follow-up care for pediatric cancer survivors. Pediatrics. 2009; 123: 906-915.

PubMed: https://www.ncbi.nlm.nih.gov/pubmed/19255020

13. Aslett $H$, Levitt $G$, Richardson A, Gibson F. A review of long-term follow-up for survivors of childhood cancer. Eur J Cancer. 2007; 43: 1781-1790. PubMed: https://www.ncbi.nlm.nih.gov/pubmed/17543515

14. Leisenring WM, Mertens AC, Armstrong GT, Stovall MA, Neglia JP, et al. Pediatric cancer survivorship research: experience of the childhood cancer survivor study. J Clin Oncol. 2009; 27: 2319-2327.

PubMed: https://www.ncbi.nlm.nih.gov/pubmed/19364957

15. Skinner R, Wallace WH, Levitt GA; UK Children's Cancer Study Group Late Effects Group. Long-term follow-up of people who survived cancer during childhood. Lancet Oncol. 2006; 7: 489-498.

PubMed: https://www.ncbi.nlm.nih.gov/pubmed/16750499

16. Kremer LC, Mulder RL, Oeffinger KC, Bhatia S, Landier W, et al. A worldwide collaboration to harmonize guidelines for the long-term follow-up of childhood and young adult cancer survivors: a report from the international late effects of childhood cancer guideline harmonization group. Pediatr Blood Cancer. 2013; 60: 543-549. PubMed: https://www.ncbi.nlm.nih.gov/pubmed/23281199

17. Horowitz ME, Fordis M, Krause S, McKellar J, Poplack DG. Passport for care: implementing the survivorship care plan. J Oncol Pract. 2009; 5: 110-112.

PubMed: https://www.ncbi.nlm.nih.gov/pubmed/20856747

18. Poplack DG, Fordis M, Landier W, Bhatia S, Hudson MM, et al. Childhood cancer survivor care: development of the passport for care. Nat Rev Clin Oncol. 2014; 11: 740-750.

PubMed: https://www.ncbi.nlm.nih.gov/pubmed/25348788

19. https://www.saccsg.co.za/. 2019.

20. http://www.survivorshipguidelines.org/pdf/2018/COG_LTFU_ Guidelines_v5.pdf. 2019.
21. https://www.skion.nl/workspace/uploads/vertaling-richtlijn-LATERversie-final-okt-2014_2.pdf. 2019.

22. https://www.uhb.nhs.uk/Downloads/pdf/CancerPbTherapyBasedLongTermFollowUp.pdf. 2019.

23. Asdahl PH, Winther JF, Bonnesen TG, De Fine Licht S, Gudmundsdottir T, et al. The Adult Life after Childhood Cancer in Scandinavia (ALiCCS) study: design and characteristics. Pediatr Blood Cancer. 2015; 62: 2204-2210.

PubMed: https://www.ncbi.nlm.nih.gov/pubmed/26193842

24. Hawkins MM, Lancashire ER, Winter DL, Frobisher C, Reulen RC, et al. The British Childhood Cancer Survivor Study: Objectives, methods, population structure, response rates and initial descriptive information. Pediatr Blood Cancer. 2008; 50: 1018-1025.

PubMed: https://www.ncbi.nlm.nih.gov/pubmed/17849473

25. HJ van der Pal. Late effects clinics and follow-up within DCOG LATER in the Netherlands. Klin Pädiatr. 2012; 224-A4.

26. Kuehni CE, Rueegg CS, Michel G, Rebholz CE, Strippoli MP, et al. Cohort Profile: The Swiss Childhood Cancer Survivor Study. Int J Epidemiol. 2012; 41: 1553-1564.

PubMed: https://www.ncbi.nlm.nih.gov/pubmed/22736394

27. Winther JF, Kenborg L, Byrne J, Hjorth L, Kaatsch P, et al. Childhood cancer survivor cohorts in Europe. Acta Oncol. 2015; 54: 655-668. PubMed: https://www.ncbi.nlm.nih.gov/pubmed/25813473

28. Taylor A, Hawkins M, Griffiths A, Davies H, Douglas C, et al. Long-term follow-up of survivors of childhood cancer in the UK. Pediatr Blood Cancer. 2004; 42: 161-168.

PubMed: https://www.ncbi.nlm.nih.gov/pubmed/14752881

29. Wallace WH, Thompson L, Anderson RA; Guideline Development Group. Long term follow-up of survivors of childhood cancer: summary of updated SIGN guidance. BMJ. 2013; 346: 1-4.

PubMed: https://www.ncbi.nlm.nih.gov/pubmed/23535255

30. Gan HW, Spoudeas HA. Long-term follow-up of survivors of childhood cancer (SIGN Clinical Guideline 132). Arch Dis Child Educ Pract Ed. 2014; 99: 138-143.

PubMed: https://www.ncbi.nlm.nih.gov/pubmed/24639409

31. Debling D, Spix C, Blettner M, Michaelis J, Kaatsch P. The cohort of long-term survivors at the German childhood cancer registry. Klin Padiatr. 2008; 220: 371-377.

PubMed: https://www.ncbi.nlm.nih.gov/pubmed/18949673

32. MacDonald L, Fryer $\mathrm{C}, \mathrm{McBride} \mathrm{ML}$, et al. The need for long-term followup of childhood cancer survivors in British Columbia. BC Medical J. 2010; 52: 504-509.

33. https://ccss.stjude.org/learn-more.html. 2019.

34. Nathan PC, Schiffman JD, Huang S, Landier W, Bhatia S, et al. Childhood cancer survivorship educational resources in North American pediatric hematology/oncology fellowship training programs: a survey study. Pediatr Blood Cancer. 2011; 57: 1186-1190.

PubMed: https://www.ncbi.nlm.nih.gov/pubmed/21674761

35. Tacyildiz N, Ozdemir S, Unal EC, et al. Barriers and solutions of longterm follow up of childhood cancer survivors in Turkey: A questionnaire survey. J Clin Oncol. 2017; 35: e22020-e22020.

36. https://www.cmsa.co.za/view_exam.aspx?QualificationID=91. 2019

37. Stricker CT, Jacobs LA, Risendal B, Jones A, Panzer S, et al. Survivorship care planning after the Institute of Medicine recommendations: how are we faring? J Cancer Surviv. 2011; 5: 358-370. PubMed: https://www.ncbi.nlm.nih.gov/pubmed/21968543

38. Anderson RA, Weddell A, Spoudeas HA, Douglas C, Shalet SM, et al. Do 
doctors discuss fertility issues before they treat young patients with cancer? Hum Reprod. 2008; 23: 2246-2251.

PubMed: https://www.ncbi.nlm.nih.gov/pubmed/18614615

39. Forman EJ, Anders CK, Behera MA. Pilot Survey of Oncologists Regarding Treatment-Related Infertility and Fertility Preservation in Female Cancer Patients. J Reprod Med. 2009; 54: 203-207. PubMed: https://www.ncbi.nlm.nih.gov/pubmed/19438160

40. Langeveld NE, Grootenhuis MA, Voûte PA, de Haan RJ, van den Bos C. Quality of life, self-esteem and worries in young adult survivors of childhood cancer. Psychooncology. 2004; 13: 867-881.

PubMed: https://www.ncbi.nlm.nih.gov/pubmed/15386796

41. Kadan-Lottick NS, Robison LL, Gurney JG, Neglia JP, Yasui Y, et al Childhood cancer survivors' knowledge about their past diagnosis and treatment: Childhood Cancer Survivor Study. JAMA. 2002; 287: 18321839.

PubMed: https://www.ncbi.nlm.nih.gov/pubmed/11939869

42. Hohmann C, Borgmann-Staudt A, Rendtorff R, Reinmuth S, Holzhausen $S$, et al. Patient counselling on the risk of infertility and its impact on childhood cancer survivors: results from a national survey. J Psychosoc Oncol. 2011; 29: 274-285.

PubMed: https://www.ncbi.nlm.nih.gov/pubmed/21590573

43. Zebrack BJ, Casillas J, Nohr L, Adams H, Zeltzer LK. Fertility issues for young adult survivors of childhood cancer. Psychooncology. 2004; 13: 689-699.

PubMed: https://www.ncbi.nlm.nih.gov/pubmed/15386645

44. Berendsen AJ, Groot Nibbelink A, Blaauwbroek R, Berger MY, Tissing WJ. Second cancers after childhood cancer - GPs beware! Scand J Prim Health Care. 2013; 31: 147-152.

PubMed: https://www.ncbi.nlm.nih.gov/pubmed/23906108

45. Han JW, Kim HS, Kim BS, Kwon SY, Shin YJ, et al. Increasing and Worsening Late Effects in Childhood Cancer Survivors during Followup. J Korean Med Sci. 2013; 28: 755-762.

PubMed: https://www.ncbi.nlm.nih.gov/pubmed/23678269

46. Aung L, Khyne T, Yeoh AE, Quah TC, Tan AM. A report from the Singapore Childhood Cancer Survivor Study (SG-CCSS): a multiinstitutional collaborative study on long-term survivors of childhood cancer, initial analysis reporting for the SG-CCSS. Ann Acad Med Singapore. 2009; 38: 684-689.

PubMed: https://www.ncbi.nlm.nih.gov/pubmed/19736571
47. Pakakasama S, Veerakul G, Sosothikul D, Chainansamit SO, Laosombat $V$, et al. Late effects in survivors of childhood acute lymphoblastic leukemia: a study from Thai Pediatric Oncology Group. Int J Hematol. 2010; 91: 850-854.

PubMed: https://www.ncbi.nlm.nih.gov/pubmed/20490729

48. Rajendranath R, Veeraiah S, Ramesh A, Sagar TG. Late effects of treatment in survivors of childhood cancer from a tertiary cancer center in South India. South Asian J Cancer. 2014; 3: 60-65. PubMed: https://www.ncbi.nlm.nih.gov/pubmed/24665450

49. Blaauwbroek R, Tuinier W, Meyboom-de Jong B, Kamps WA, Postma A. Shared care by paediatric oncologists and family doctors for long-term follow-up of adult childhood cancer survivors: a pilot study. Lancet Oncol. 2009; 9: 232-238.

PubMed: https://www.ncbi.nlm.nih.gov/pubmed/18282804

50. Blaauwbroek R, Barf HA, Groenier KH, Kremer LC, van der Meer K, et al. Family doctor-driven follow-up for adult childhood cancer survivors supported by a web-based survivor care plan. J Cancer Surviv. 2012; 6: 163-171.

PubMed: https://www.ncbi.nlm.nih.gov/pubmed/22124938

51. Shad A, Myers SN, Hennessy K. Late effects in cancer survivors: "the shared care model". Curr Oncol Rep. 2012; 14: 182-190.

PubMed: https://www.ncbi.nlm.nih.gov/pubmed/22286374

52. Ishida $Y$, Takahashi M, Maru M, Mori M, Henderson TO, et al. Physician Preferences and Knowledge Regarding the Care of Childhood Cancer Survivors in Japan: A Mailed Survey of the Japanese Society of Pediatric Oncology. J Clin Oncol. 2010; 28: 878-883.

PubMed: https://www.ncbi.nlm.nih.gov/pubmed/22457322

53. Henderson TO, Hlubocky FJ, Wroblewski KE, Diller L, Daugherty CK. Physician Preferences and Knowledge Gaps Regarding the Care of Childhood Cancer Survivors: A Mailed Survey of Pediatric Oncologists. J Clin Oncol. 2010; 28: 878-883.

PubMed: https://www.ncbi.nlm.nih.gov/pubmed/20038717

54. Pannier ST, Mann K, Warner EL, Rosen S, Acharya A, et al. Survivorship care plan experiences among childhood acute lymphoblastic leukemia patients and their families. BMC Pediatr. 2019; 19: 111. PubMed: https://www.ncbi.nlm.nih.gov/pubmed/30979365

55. http://www.health.gov.za/index.php/nhi. 2019. 